\title{
FinANCIALLY INTERLINKED BUSINESS GROUPS*
}

\author{
Maitreesh GhataK \\ University of Chicago
}

RAJA KALI

Sam M. Walton College of Business

University of Arkansas, Fayetteville, AR 72701

RKali@Walton.uark.edu

Financial interlinkage, in the form of cross-holding of equity and debt between firms, characterizes business groups in many countries. We suggest that such financial interlinkage can be viewed as a way to solve credit rationing caused by asymmetric information. If firms possess better information about each other than a bank, then business groups can be a mechanism to induce firms to sort on the basis of this information. Banks can offer a menu of contracts that vary in the extent of financial interlinkage to induce firms to self-select on the basis of the equilibrium composition of the business groups they can form.

\section{INTRODUCTION}

Business groups feature prominently in the industrial organization of many countries, both developed and developing. Reflecting the widespread prevalence of these organizations is the diversity in the way they are defined. ${ }^{1}$ The ties that bind group firms range from administrative and financial linkages to those grounded in family, ethnicity, society, religion, and region. While it is the diversity in these factors that leads to the subtle external differences between business groups in different countries, a common internal thread is the interlinkage in equity and debt among the firms that constitute the group. It is this kind of financial interlinkage that is the focus of this paper. Our objective here is to present a theory of business groups based on the cross-holding of equity and debt.

We thank two anonymous referees for detailed comments that significantly improved the paper, as well as Sugato Bhattacharya, Enrico Perotti, Tarun Khanna, and participants at the 2000 Financial Market Development for Emerging and Transition Economies Conference at LBS for helpful comments. We are grateful to the James $\mathrm{H}$. Penick endowment for financial support of this research. The usual disclaimer applies.

1 . The emphasis is on "... an intermediate level of binding - excluding, on the one hand, a set of firms bound merely by short-term strategic alliances and, on the other, a set of firms legally consolidated into a single one." See Granovetter (1994). 
The existence of financial interlinkages between the constituent firms of a business group has been widely noted. Previous explanations of these interlinkages have focused on the role played by cross-shareholding in either providing risk sharing (see, for example, Goto, 1982; Brioschi, et al., 1989; Nakatani, 1984; Kali, 1999b), softening intensity of competition between firms in imperfect product markets (see Clayton and Jorgensen, 2000), or in mitigating moral-hazard problems within the group (see Aoki, 1982; Berglof and Perotti, 1994).

What has been overlooked is the cross-holding of external debt that often accompanies the cross-holding of equity among the firms that constitute the business group. Sometimes referred to as crosspayment guarantees or mutual debt guarantees, these imply that if a member firm is on the verge of defaulting on an external loan, the other group firms will each pay a fraction of the defaulting firm's external debt provided they are in a position to do so.

Cross-guarantees of this kind are prevalent within business groups in several emerging economies. In their study of the financing constraints of Korean chaebols, Shin and Park (1999) emphasize the role played by intragroup cross-guarantees in supporting external bank lending. ${ }^{2}$ Such practices are also prevalent within Chinese business groups. Keister's (2000) extensive study of Chinese business groups describes the importance of mutual debt relationships in times of financial adversity and how they ease credit constraints in the absence of a well-developed financial market. A recent econometric study by Khanna and Yafeh (1999) documents the importance of intragroup loans as a mechanism by which group firms assist each other in times of financial distress in India. Casteñeda's (1998) study of Mexican business groups also notes the existence of loan guarantees among member firms of the business group. Mutual debt guarantees play an important role in the theory we develop here, in addition to the cross-holding of equity.

Our theory suggests that business groups that are financially interlinked through cross-shareholding and cross-guarantee of loans can be viewed as a way to obviate credit rationing caused by asymmetric information. If all firms possess better information about the types of some other firms than the bank, then financially interlinked business groups can be a mechanism to induce firms to sort on the

2. For example, according to the Bank of (South) Korea, in 1991, cross-payment guarantees by the top five chaebol (13 companies) amounted to 19.9 trillion won, and by the top 30 chaebol (76 companies) 38.3 trillion won ( 1 US dollar $=1113$ Korean won, June 2000). Samsung's three core companies ranked first, with combined payment guarantees of 5.8 trillion won, followed by Daewoo's core companies with 5.4 trillion won. See Business Korea, 9 (9), 22, 1992. 
basis of this information. Consequently, banks can offer a menu of contracts that vary in the extent of financial interlinkage to induce firms to self-select on the basis of the equilibrium composition of the business groups they can form. By accessing information firms may possess about each other, financial interlinkage among business groups can improve efficiency in the credit market. ${ }^{3}$

The starting point for our theory is the well-known lemon problem that arises in credit markets with asymmetric information between borrowers and lenders (see Stiglitz and Weiss, 1981; De Meza and Webb, 1987). In the presence of adverse selection in the credit market, the equilibrium allocation with standard debt contracts may be inefficient - deserving projects may not get funded [the underinvestment problem of Stiglitz and Weiss (1981)] or undeserving projects may get funded [the overinvestment problem of De Meza and Webb (1987)]. But what if firms, which are better equipped than outside lenders to judge project riskiness, are allowed to have cross-holding of equity and debt guarantees, thus forming business groups characterized by financial interlinkage? In this event, we show that by offering contracts that involve financial interlinkage along with standard debt contracts, lenders can induce borrowers to form groups that display assortative matching and self-select among these contracts. In particular, in the presence of mutual debt guarantees, high-risk borrowers will not be able to induce low-risk borrowers to associate with them even if side payments are allowed. The intuition is simple: while any type of firm will prefer to have a low-risk firm in its group, the value from having a low-risk member is strictly higher for low-risk firms, since they are themselves less likely to default, and hence more likely to have to pay the debt guarantee amount for a defaulting member. Business groups are therefore formed of firms with similar characteristics. This idea is expressed more formally as Proposition 1 of the model.

We then examine the properties of these business groups. Corollary 1 expresses the finding that the isocost curves of business groups formed as a result of the positive assortative matching display the single-crossing property. In particular, for a given reduction in the interest rate, a low-risk firm will be willing to offer a higher debt guarantee on the loans of its member firms, since it has low-risk firms in its group. Consequently, an outside lender can use this property to

3. It is important to emphasize that our focus is on reciprocal shareholding and debt guarantees that are the pattern among horizontal groups. This is distinct from a unidirectional chain of shareholding as in a pyramidal structure. There is an extensive literature on pyramidal structures. See, for example Wolfenzon (1999), Bebchuk et al. (1998), and La Porta et al. (1999). 
offer a menu of contracts to sort the business groups by quality of investment projects. Low-risk business groups will pay lower interest rates but engage in a higher degree of cross-holding than business groups with higher-risk projects.

Starting from a situation where, under standard debt contracts, projects with negative social surplus are borrowing, by offering appropriate financially interlinked contracts, lenders can exclude these projects from the credit market. Conversely, if firms with low-risk projects do not find it worthwhile to finance their projects when faced with a standard pooled debt contract, they can be attracted back into the market using financially interlinked contracts, thereby enhancing efficiency. Proposition 2 expresses this idea.

Mutual debt guarantees are the driving force behind the results mentioned above. We extend our basic model in two different ways to explain mutual equity cross-holdings, one based on mutual monitoring among group members, and the other based on risk sharing. With these extensions we provide explanations for equity cross-holdings and show at the same time that the assortative matching and screening results in our basic model due to mutual debt guarantees continue to hold.

Our paper has links to several different literatures. It contributes to the understanding of business groups, a literature that has been recently reinvigorated by the interest in the industrial organization of developing and transition countries (see Ghemawat and Khanna, 1998; Khanna and Palepu, 1998a; Kali 1999b). Within this literature our paper is closest in spirit to Berglof and Perotti's (1994) analysis of the Japanese financial keiretsu. Their model focuses on the role of crossshareholding among firms within a group to provide the incentive to monitor as well as the means, through reciprocal voting rights and coalition-enforced threats of removal. To guard against the possibility of collusive behavior by the coalition as whole (namely, no manager exerts effort, and all vote their firms' cross-holdings to protect current managerial appointment), the role of external debt from the group bank is emphasized. Poor profitability results in financial distress, and the control of the firm is shifted to the main lender, moving away from mutual governance by cross-shareholders. Unlike that paper, the main focus of our paper is cross-holding of debt and how it can resolve adverse-selection problems. However, the extension of our baseline model in Section 2.3 is similar to their explanation of cross-holding of equity, although the formal models are different. Their paper analyzes the problem of ex post moral hazard, and how it can be alleviated in a repeated-game setup through cross-holdings of equity, which through reciprocal exchange of voting rights allows firms to punish a manager 
who shirks. We focus on ex ante moral hazard in a static model and show how cross-holdings of equity are a way to directly induce the manager of a firm to monitor the manager of another firm.

A recent paper by Clayton and Jorgensen (2000) provides a different explanation for cross-holding of equity than the ones offered by Berglof and Perotti and our paper. They show that in the presence of Cournot quantity competition in the product market, cross-equity holdings can lead to higher joint profits by inducing each firm to internalize the effect of its quantity decision on the profits of the other firm. Our result on assortative matching can also be compared with a recent paper by Matsusaka (2000) that models the diversification decision of firms as a search problem by which firms seek businesses that are good matches for their capabilities. The main difference between these two models is that sorting (between firms) in our model is induced not by any technological features, but by a contractual feature.

Our paper is also related to the literature on the problem of adverse selection in credit markets, and the role of collateral and mutual loan guarantees in alleviating this problem. In the economic history literature, analyzing the banking insurance experience in the US during the antebellum period and the 1920s, Calomiris (1990) finds evidence of mutual-liability-based bank insurance schemes being more successful than others. In the banking literature, Bester (1987) shows that collateralization of loans can ameliorate adverse-selection problems by screening borrowers by riskiness of project. In particular, safe borrowers will be willing to offer greater collateral than risky borrowers for a given reduction in the interest rate, because they expect to repay (and hence not lose the collateral) more often. If borrowers are too poor to offer collateral, then the problem of adverse selection can lead to inefficiencies in the allocation of credit. Inspired by the successful experience of the Grameen Bank of Bangladesh in lending to poor villagers without any collateral by asking borrowers to form self-selected groups and making the group members jointly liable for each other's loans, several recent papers in the development economics literature have examined how this mechanism can solve various informational problems [see Morduch (1999) for a recent survey]. In particular, joint liability can be used as an instrument to sort borrowers according to the riskiness of their projects (see, for example, Ghatak, 2000).

While our paper is similar in spirit to this literature, there are several differences. First, joint liability in the context of microlending takes the form of denying future credit to the entire group if any member defaults, which is quite different from cross-holding or mutual guarantee of debt. Second, there is no cross-holding of equity 
among borrowers within a group, and we demonstrate here that assortative matching and sorting is robust to the introduction of equity interlinkage.

Our paper demonstrates that financial interlinkage through equity and debt cross-holding can be efficiency-improving in some circumstances. This is in contrast to the minority-expropriation view of financial interlinkage put forward in the literature on pyramidal structures (such as La Porta et al., 1999). However, it is important to note that the environment we are concerned with involves reciprocal shareholding and debt guarantees, while pyramids are unidirectional chains of shareholding. ${ }^{4}$ A recent paper by Wolfenzon (1999) develops a theory of pyramidal ownership and its implications for extraction and firm value. ${ }^{5}$

We have organized the remainder of the paper in the following way. Section 2 presents the basic model and considers various extensions of it. Section 3 explores empirical implications of the model and concludes.

\section{THE MODEL}

We develop a simple static model of adverse selection in the credit market, similar to Stiglitz and Weiss (1981) and De Meza and Webb (1987). The economy consists of a continuum of risk-neutral entrepreneurs normalized to unity. Each entrepreneur is the owner of a blueprint for an investment project that requires a capital outlay for the purchase of productive assets. These assets can then be combined with entrepreneurial labor to produce a return on the investment. There is no moral hazard, and entrepreneurs supply labor to the project inelastically. Once the capital is in place and the required unit of labor is put in, projects yield either a high or a low return. We refer to these outcomes as success $(S)$ and failure $(F)$, respectively. There are two exogenously given types of entrepreneurs, characterized by the probabilities of success of their projects, $p_{r}$ and $p_{s}$, where

$0<p_{r}<p_{s}<1$.

Henceforth we will refer to them as risky and safe entrepreneurs. Risky and safe entrepreneurs exist in proportions $\theta$ and $1-\theta$ in the popu-

4. Several recent studies (see Khanna, 2000) cast doubt on economists' equation of groups and pyramids.

5. We also focus solely on financial interlinkage as a solution to asymmetric information problems in credit, but there can be, of course, other economic functions that business groups perform. In situations with imperfect markets for labor and capital, business groups are able to act as surrogate labor markets and venture capitalists. See Khanna and Palepu (1998a) for more detailed arguments. Further theoretical work will try to account for these functions explicitly. 
lation. The outcomes of the projects are assumed to be independently distributed for the same types as well as across different types. The return of a project is $R>0$ if it is successful and 0 if it fails for both types of projects. Our formulation of how risky and safe projects differ is similar to De Meza and Webb (1987). In Stiglitz and Weiss (1981), in contrast, risky and safe projects are assumed to have the same mean return, but risky projects have a greater spread around the mean. Our main results extend easily to this case, as we discuss at the end of Section 3.

Entrepreneurs have no wealth and hence have to rely on external finance. An entrepreneur who chooses not to use his blueprint obtains the reservation payoff $u$. We use the terms entrepreneur and firm interchangeably in the paper. There is a risk-neutral external lender, which we will refer to as a bank, that can provide investment financing to each entrepreneur at a gross (inclusive of principal) interest rate $r$. Borrowers have limited liability. So if their projects fail, entrepreneurs are liable up to the amount of collateralizable wealth they possess, which we take to be zero for simplicity. The opportunity cost of capital for the bank is $\rho$ per loan. We assume it is economically efficient to pursue only safe investment projects:

\section{ASSUMPTION 1:}

$p_{s} R-u-\rho>0>p_{r} R-u-\rho$.

Following existing models of adverse selection in the credit market, we will focus only on debt contracts. ${ }^{6}$

The type of each borrower is unknown to the bank. However, each entrepreneur possesses some information about a group of other entrepreneurs. Specifically, the type of each entrepreneur belonging to the same information network is common knowledge within the network. We could think of each entrepreneur as belonging to such an informational network because of being a member of a social or ethnic group. ${ }^{7}$

6. In this model, there is no difference between debt and equity contracts. When a borrower fails, she pays nothing, whereas when she succeeds she pays a positive amount to the bank. Since both types of borrowers earn the same revenue when their projects succeed, whether the bank is paid a fraction of the success revenue, or an amount independent of it, makes no difference. In contrast in Stiglitz and Weiss's model, risky and safe borrowers earn different amounts of revenue when their projects succeed. As a result, debt and equity contracts have different implications.

7. These informational networks may or may not be connected with one another. 


\subsection{The AdVerse-Selection Problem}

In the environment that we have specified, simple debt contracts may run into the following type of adverse-selection problem. The reasoning is straightforward. Because the bank cannot identify ex ante which blueprints are better and which are worse, it will offer a pooling contract to all entrepreneurs based on the average repayment rate in the population, $\bar{p} \equiv \theta p_{r}+(1-\theta) p_{s}$. Thus the bank will charge an interest rate $\bar{r}=\rho / \bar{p}$. However, it is possible that projects that are not worthy of being financed from the point of view of economic efficiency may be financed at this interest rate. We assume this condition to hold:

\section{AsSuMPTION 2:}

$p_{r}\left(R-\frac{\rho}{\bar{p}}\right)>u$.

Notice that this condition may hold even when risky projects are unproductive (i.e., $p_{r} R-u-\rho<0$ ), because they are cross-subsidized by safe borrowers. Here the average repayment rate would be $\bar{p}$ and the level of expected social surplus would be $\theta\left\{p_{r}(R-\rho / \bar{p})-u\right\}+(1-$ $\theta)\left\{p_{s}(R-\rho / \bar{p})-u\right\}=\bar{p} R-\rho-u=\theta\left(p_{r} R-\rho-u\right)+(1-\theta)\left(p_{s} R-\right.$ $\rho-u)$. If the bank had perfect information about the type of a firm, then it would lend to safe firms only, leading to an average repayment rate of $p_{s}$, and the level of expected social surplus would be $(1-\theta)\left(p_{s} R-\rho-u\right)$. Given (1), both these surpluses are strictly higher than those achieved under adverse selection. This is the overinvestment problem in credit markets with adverse selection (De Meza and Webb, 1987). Notice that while social surplus is higher when risky firms are excluded, welfare comparisons are less clear-cut. Safe borrowers are better off under the full-information allocation (since they have to cross-subsidize risky borrowers under the pooling debt contract), while risky borrowers are strictly worse off.

\subsection{FINANCIAL INTERLINKAGE AND AsSORTATIVE MATCHING}

In this section we explain how the cross-holding of equity and debt between firms can be a solution to the adverse-selection problem in the market for credit. A set of firms that are interlinked through debt and equity in this fashion is what we refer to as a business group. 
2.2.1 Assortative Matching and Single Crossing. First we show that for any given interest rate $r$, firms with debt and equity cross-holding will always choose business-group partners of the same type. That is, the equilibrium in the group-formation game satisfies the optimal-sorting property, namely, firms not in the same business group cannot form a business group without making at least one of them worse off. Our proof of this property explicitly allow firms to be able to make side payments to each other. In principle then, a risky firm can pay a safe firm to join its business group. For simplicity, we will consider groups of size two. ${ }^{8}$

Let $\pi_{i j}$ denote the expected payoff of an entrepreneur of type $i$ who forms a business group with an entrepreneur of type $j$. We focus on symmetric equity stakes here, and consider the implications of relaxing this assumption in Section 2.5. Let $\alpha$ be the share of his own project returns that he retains; $1-\alpha$ is his stake in his partner's firm. Let $0 \leq \gamma \leq 1$ be the extent of the liability that a firm in the business group has on a member firm's loans. In the event that a project in which an entrepreneur is a shareholder fails and goes bankrupt, the entrepreneur will pay a fraction $\gamma$ of the failed firm's debt obligation.

Then,

$$
\begin{aligned}
\pi_{i j}= & p_{i} p_{j}\{\alpha(R-r)+(1-\alpha)(R-r)\}+p_{i}\left(1-p_{j}\right) \alpha(R-r-\gamma r) \\
& +p_{j}\left(1-p_{i}\right)(1-\alpha)(R-r-\gamma r) \\
= & \{R-(1+\gamma) r\}\left\{\alpha p_{i}+(1-\alpha) p_{j}\right\}+p_{i} p_{j} \gamma r .
\end{aligned}
$$

Thus, if a risky firm were to switch from forming a business group with a risky partner to one with a safe partner instead, the expected gain would be

$\pi_{r s}-\pi_{r r}=\left(p_{s}-p_{r}\right)\left[(1-\alpha)\{R-(1+\gamma) r\}+p_{r} \gamma r\right]$.

Similarly, if a safe firm were to switch from forming a business group with a safe partner to one with a risky partner instead, the expected loss would be

$\pi_{s s}-\pi_{s r}=\left(p_{s}-p_{r}\right)\left[(1-\alpha)\{R-(1+\gamma) r\}+p_{s} \gamma r\right]$.

The question now is whether the gain for the risky entrepreneur from forming a group with the safe entrepreneur is greater than the loss that the safe entrepreneur incurs from agreeing to allow risky entrepreneurs to form a group with him. If this is so, then the risky 
entrepreneurs can negotiate a bribe for the safe entrepreneurs that will induce them to team with the risky entrepreneurs and will make both parties better off. However, since $p_{s}>p_{r}$, comparing the two expressions, we see that

$\pi_{s s}+\pi_{r r}>\pi_{r s}+\pi_{s r}$

and therefore business-group formation will display positive assortative matching.

Consequently, as in Becker's (1993) analysis of the marriage market, entrepreneurs in our model will form business groups with financial interlinkage only with those who have a similar risk profile. The intuition is the following. From the point of view of both types of borrowers, a safe partner is preferred both because of higher expected returns through cross-shareholding and lower expected liability on their loans through the cross-guarantee of loans. However, as far as cross-shareholding is concerned, the gain of a risky type from having a safe partner is exactly equal to the loss of a safe type from having a risky partner. As a result, with side payments being possible, firms will be indifferent between choices of partners. However, as far as cross-guarantee of loans is concerned, a safe firm will have a higher valuation of having a safe partner in the business group than a risky firm. This is because the benefit of having a safe rather than a risky partner is realized only when a firm does not itself default, and the probability of this is high for safe firms. This implies that a risky firm will never find it profitable to attract a safe firm to be a group member after compensating the latter for the loss of having a risky firm as a partner. We can state the preceding analysis in the form of the following proposition.

Proposition 1: Financial interlinkage within business groups in the form of cross-shareholding and cross-guarantee of loans leads to positive assortative matching in the formation of business groups.

Given assortative matching, in equilibrium the payoff of each type of entrepreneur under a contract $(r, \gamma)$ will be

$\pi_{i i}(\gamma, r)=\{R-(1+\gamma) r\} p_{i}+p_{i}^{2} \gamma r, \quad i=s, r$.

Hence the isocost curve of an entrepreneur of type $i$ in $(\gamma, r)$ space is represented by $p_{i}(1+\gamma) r-p_{i}^{2} \gamma r=k, i=s, r$, where $k$ is a constant. The slope of an isocost curve of an entrepreneur of type $i$ is then

$\frac{d r}{d \gamma}=-r\left\{\frac{1}{\frac{1}{1-p_{i}}+\gamma}\right\}<0, \quad i=s, r$.

Since $p_{s}>p_{r}$, the isocost curve for the safe entrepreneur is flatter than one for the risky entrepreneur in the $(\gamma, r)$ plane. That is, the 


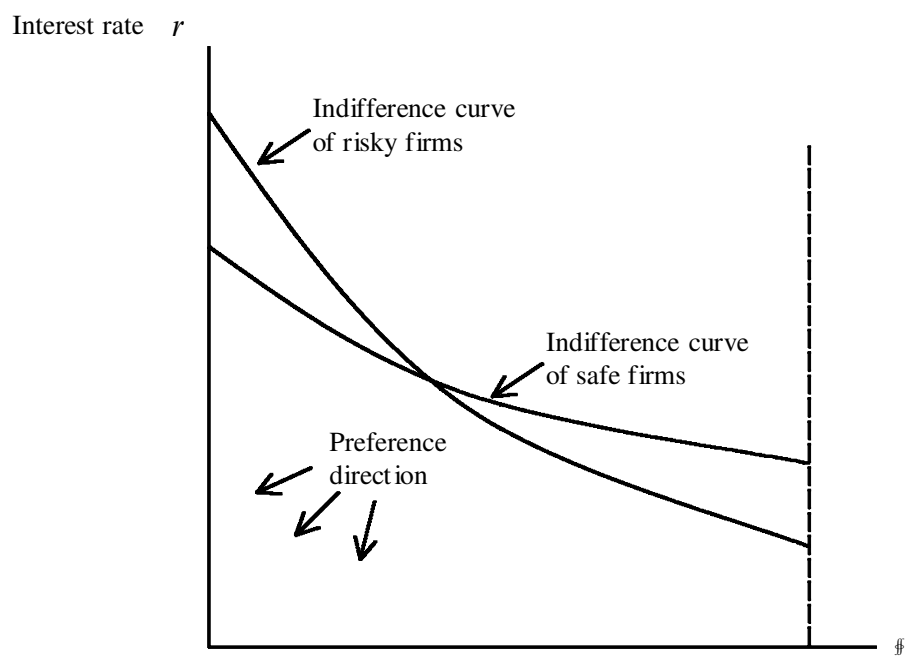

Cross liability

FIGURE 1.

isocost curves satisfy the single-crossing property, which implies that by offering a menu of contracts that vary in $r$ and $\gamma$, banks can induce various business groups to self-select.

COROLlaRY 1: Isocost curves of firms satisfy the single-crossing property in the $(\gamma, r)$ plane.

Figure 1 represents these isocost curves.

Since the isocost curves are negatively sloped, the higher is the interest rate $r$, the lower will have to be the degree of cross-guarantee of loans, $\gamma$. It also follows that to receive a small reduction in the interest rate, safe firms will be willing to offer a higher degree of cross-guarantee than risky firms, because they have safe partners.

Banks can use this property to screen firms by offering contracts to business groups that differ in the interest rate $r$ and the degree of cross-guarantee, $\gamma$. We show that this can improve social surplus by driving out risky firms that were not initially borrowing under the standard debt contract.

Two observations are worth making regarding the assortativematching result and the single-crossing property before we move on to derive optimal screening contracts. First, our proof relies only on firms having different probabilities of success, and on their types (i.e., probabilities of success) being complementary in the payoff function 
induced by a financial interlinkage. ${ }^{9}$ In particular, it does not depend on whether safe and risky firms have the same or different expected project returns, and hence this result extends to Stiglitz and Weiss's environment as well. Second, and related to the previous observation, the extent of equity-cross holding plays no role in these proofs either (i.e., they go through for every value of $\alpha$ ). Even if there were no cross-holding of equity, these results would continue to hold.

In Section 2.3 where we discuss extensions of the current model, we outline two alternative theories of equity-cross holding, one based on mutual monitoring, and the other on risk sharing. In particular, we show that the assortative-matching result and the single-crossing property continue to hold in these extensions.

2.2.2 Optimal Screening Contracts. Next, we derive optimal screening contracts. To do so, first we need to prove the following lemma:

LEMMA 1: If the contracts $\left(\gamma_{r}, r_{r}\right)$ and $\left(\gamma_{s}, r_{s}\right)$ are incentive-compatible, then assortative matching will still result in the formation of business groups.

Proof. Suppose not. Then it must be that two heterogeneous groups earn greater joint profits by borrowing under either of the two contracts that are offered [say, $\left(\gamma_{s}, r_{s}\right)$ ] than two homogeneous groups can earn under the contracts $\left(\gamma_{r}, r_{r}\right)$ and $\left(\gamma_{s}, r_{s}\right)$, that is,

$\pi_{r s}\left(\gamma_{s}, r_{s}\right)+\pi_{s r}\left(\gamma_{s}, r_{s}\right)>\pi_{r r}\left(\gamma_{r}, r_{r}\right)+\pi_{s s}\left(\gamma_{s}, r_{s}\right)$

By Proposition 1, if the contract $\left(\gamma_{s}, r_{s}\right)$ had been the only one offered by the bank, assortative matching would have resulted. That is,

$\pi_{r r}\left(\gamma_{s}, r_{s}\right)+\pi_{s s}\left(\gamma_{s}, r_{s}\right)>\pi_{r s}\left(\gamma_{s}, r_{s}\right)+\pi_{s r}\left(\gamma_{s}, r_{s}\right)$

Together these inequalities imply $\pi_{r r}\left(\gamma_{s}, \gamma_{s}\right)>\pi_{r r}\left(\gamma_{r}, r_{r}\right)$. But that violates the incentive compatibility constraint for risky firms, a contradiction.

9. That is, $\partial^{2} \pi_{i, j}(r, \gamma) / \partial p_{i} \partial p_{j}=\gamma r>0$. Technically, this is the reason why positive assortative matching results with such a contractual form. Becker's analysis showed that if the cross partial derivatives of the types of agents are negative, then negative assortative matching results. In the context of business groups, if we allow for a more general production technology such that member firms have comparative advantage in different tasks (or products) and these enter a joint production function of the group as a whole, then we could have positive or negative assortative matching, depending on whether these tasks are strategic complements or substitutes. 
Our goal is to find a pair of contracts $\left(\gamma_{s}, r_{s}\right)$ and $\left(\gamma_{r}, r_{r}\right)$ such that risky borrowers do not borrow. Without loss of generality we can take $\left(\gamma_{r}, r_{r}\right)=\left(0, \rho / p_{r}\right)$, the same contract they would be offered under full information. The bank's zero-profit condition from lending to safe borrowers is ${ }^{10}$

$r_{s} p_{s}\left\{1+\gamma_{s}\left(1-p_{s}\right)\right\}=\rho$.

We can use this to solve for $r_{s}$ in terms of $\gamma_{s}$ :

$r_{s}=\frac{\rho}{p_{s}\left\{1+\gamma_{s}\left(1-p_{s}\right)\right\}}$.

The incentive compatibility constraint of risky borrowers require them to prefer not borrowing at all to borrowing under the contract $\left(\gamma_{s}, r_{s}\right)$ :

$p_{r}\left[R-r_{s}\left\{1+\gamma_{s}\left(1-p_{r}\right)\right\}\right] \leq u$.

Substituting (3) in (4), we get the following condition for the existence of a separating equilibrium: there exists $\gamma_{s} \in[0,1]$ such that

$p_{r} R-u \leq \frac{p_{r}\left\{1+\gamma_{s}\left(1-p_{r}\right)\right\}}{p_{s}\left\{1+\gamma_{s}\left(1-p_{s}\right)\right\}} \rho$.

Finally, we need to ensure that another condition is satisfied for the optimal cross-guarantee contract to be feasible, namely, the contract $\left(\gamma_{s}, r_{s}\right)$ must satisfy the following limited liability constraint:

$r_{s}\left(1+\gamma_{s}\right) \leq R$.

Using (3) this condition can be written as

$\frac{1+\gamma_{s}}{p_{s}\left\{1+\gamma_{s}\left(1-p_{s}\right)\right\}} \rho \leq R$.

This guarantees that a firm cannot make any transfers to the bank when its project fails, and that the sum of its own liability and the liability for member firms of the business group it belongs to through cross-guarantees, $r(1+\gamma)$, cannot exceed the realized revenue from the project when it succeeds. We assume that the following pair of conditions hold:

10. If the bank is a monopolist maximizing its expected profits, then the optimal contracts will be similar to those derived in this section, but they will lie on the respective participation constraints of the borrowers as opposed to the zero-profit constraints of the bank. 
ASSUMPTION 3:

$$
\begin{aligned}
& \frac{p_{r}}{\bar{p}} \rho+u \leq p_{r} R<\frac{p_{r}\left(2-p_{r}\right)}{p_{s}\left(2-p_{s}\right)} \rho+u, \\
& \rho+u<p_{s} R \leq \rho+\frac{p_{s}^{2}}{p_{r}^{2}} u .
\end{aligned}
$$

Observe that Assumptions 1 and 2 are implied by this assumption. ${ }^{11}$ Recall that these assumptions implied that safe projects generate positive social surplus, risky projects generate negative social surplus, and under a standard debt contract risky borrowers borrow. Then we are able to prove:

Lemma 2: Suppose Assumption 3 holds. Then there exists a pair of contracts $\left(\gamma_{s}, r_{s}\right)$ and $\left(\gamma_{r}, r_{r}\right)$ that satisfy the zero-profit condition of the bank and the limited-liability constraint such that risky borrowers do not borrow.

Proof. See the Appendix.

The solution to the optimal-separating problem will not in general be unique. We prove that there exists a critical value of the degree of optimal cross-holding of debt for safe borrowers, $\hat{\gamma} \in(0,1]$, such that for any $\gamma_{s} \geq \hat{\gamma}$ there exists a corresponding interest rate for safe borrowers, $r_{s}$ (from the bank's zero-profit condition), such that the incentive compatibility constraint of risky borrowers and the limitedliability constraint are satisfied. At the same time, so long as Assumption 3 is satisfied, it is possible to offer a pair of contracts such that only safe firms get to borrow by forming business groups with crossshareholding and cross-guarantee of loans, and risky firms do not receive loans. ${ }^{12}$

Since the contracts $\left(\gamma_{s}, r_{s}\right)$ and $\left(0, \rho / p_{r}\right)$ lie on the respective zero-profit equations, the expected payoff of a safe firm is equal to $p_{s} R-u-\rho$, and the repayment rate is equal to $p_{s}$. Hence the average repayment rate and social surplus under this pair of contracts are at their full-information levels and strictly higher than those under ordinary debt contracts. The main result of this section readily follows:

11. This is not obvious for the part of Assumption 1 that says $p_{r} R<\rho+u$. In the proof of Lemma 2 below we show that $p_{r}\left(2-p_{r}\right) / p_{s}\left(2-p_{s}\right)<1$, and so $p_{r} R<$ $\left\{p_{r}\left(2-p_{r}\right) / p_{s}\left(2-p_{s}\right)\right\} \rho+u$ implies $p_{r} R<\rho+u$.

12. A counterfactual implication of this model is that no firm borrows under a standard debt contract. In order to highlight the potential efficiency gains from financially interlinked business groups using the simplest possible model, we assumed there are only two types of borrowers, with risky borrowers having inefficient projects. This assumption can be readily relaxed to allow a third type of borrower: risky borrowers who have efficient projects. Then under the optimal screening contracts, risky borrowers who have efficient projects will borrow under the standard debt contract. 
Proposition 2: If parameters satisfy Assumption 3, financial interlinkage within business groups in the form of cross-shareholding and crossguarantee of loans will produce greater expected social surplus and repayment rates than standard debt contracts.

It is straightforward to extend this result to an environment where adverse selection leads to the exclusion of safe projects with positive net surplus from the market, as in Stiglitz and Weiss (1981), rather than the form of inefficiency we focus on (i.e., risky projects with negative net surplus receiving loans). As observed before, Proposition 1, Corollary 1, and Lemma 1 do not depend on the distribution of revenues of the projects, and hence these results continue to apply. The key difference between these two setups lies in which type of borrower's participation constraint binds. In the above model, safe types have a higher expected payoff for any given contract, and so it is the participation constraint of risky borrowers that we focus on. However, if both types of projects have the same mean returns, then safe borrowers have a lower expected payoff under a standard pooling debt contract. This is because expected interest payments to the bank are higher for safe borrowers (since they pay back the same amount more often than risky borrowers), while expected revenues are by assumption the same. Hence it is possible that under standard debt contracts, the participation constraint of safe borrowers will not be satisfied and only risky borrowers will borrow at an interest rate of $\rho / p_{r}$. If financially interlinked contracts are allowed, the bank can offer two contracts, $\left(r_{s}, \gamma_{s}\right)$ and $\left(\rho / p_{r}, 0\right)$, such that safe borrowers will choose the former, and risky borrowers will choose the latter. Notice that the welfare implication of financial interlinkage is quite different in this case. Financially interlinked contracts would attract safe firms back into the market, while risky borrowers would continue to borrow under debt contracts. As a result, the welfare of safe borrowers, social surplus, and repayment rates will all be higher, but risky borrowers would be no worse off. In contrast, in the basic model, social surplus and the welfare of safe borrowers are higher, but risky borrowers are strictly worse off with financial interlinkage.

\subsection{OPTIMAL CROSS-HOLDING OF EQUITY}

The main results in the previous section were driven by the crossholding of debt. How much a firm valued having a safe firm in its group was positively correlated with its own type due to crossholding of debt, leading to assortative matching in the formation of business groups. This in turn allowed banks to exclude risky firms with inefficient projects from borrowing, which might not have been 
possible with standard debt contracts. However, equity cross-holding is a prominent characteristic of business groups across the world, and its extent played no role in the results of the previous section. In this section we address the issue of determining the optimal degree of cross-holding of equity, using two alternative models. The first is based on mutual monitoring, and the second on risk sharing.

2.3.1 Mutual Monitoring. Consider a simple extension of our basic model where the probability of success of each type of project depends (apart from an intrinsic quality component) on the effort put in by managers of firms within a business group. In particular, the probability of success of the $i$ th type of project is now $p_{i}=\bar{p}_{i}+a+b$, where $\bar{p}_{s}>\bar{p}_{r}, a \in[0, \bar{a}]$ is the effort level chosen by the manager of a firm, and $b \in[0, \bar{b}]$ is the effort level chosen by the manager of its partner firm. A sufficient condition for $p_{i}<1$ for $i=r, s$ is $\bar{a}+\bar{b}<1-\bar{p}_{s}$. The key assumption is that $a$ and $b$ are unobservable among the managers of the firm, and to the bank. Also, these efforts are subject to some disutility costs, which are taken to be quadratic for simplicity: $\frac{1}{2} c_{1} a^{2}$ and $\frac{1}{2} c_{2} b^{2}$. The effort of the manager of a firm devoted to the project of a firm that is a member of the same business group can be interpreted as monitoring effort or as help. ${ }^{13}$ We show that (a) equity-cross holding can work as an optimal incentive device to elicit effort (or other noncontractible resources) from other group members, and (b) debt cross-holding can still be used as a screening device when the effort levels are endogenous.

Consider a given contract $(r, \gamma, \alpha)$ for cross-holding of debt and equity, and a group consisting of two types of firms, $i$ and $j$. We show that for any given contract $(r, \gamma, \alpha)$ the assortative-matching result still goes through when the effort levels are endogenous. Next, we show how a bank can screen borrowers by offering contracts that differ in the extent of cross-holding of debt and equity. For firm $i$ the decision problem is to

$$
\begin{gathered}
\max _{\left\{a_{i}, b_{i}\right\}}\{R-r(1+\gamma)\}\left\{\alpha p_{i}\left(a_{i}, b_{j}\right)+(1-\alpha) p_{j}\left(a_{j}, b_{i}\right)\right\} \\
+p_{i}\left(a_{i}, b_{j}\right) p_{j}\left(a_{j}, b_{i}\right) \gamma r-\frac{1}{2} c_{1} a_{i}^{2}-\frac{1}{2} c_{2} b_{i}^{2},
\end{gathered}
$$

where $p_{i}\left(a_{i}, b_{j}\right)=\bar{p}_{i}+a_{i}+b_{j}$ and $p_{j}\left(a_{j}, b_{i}\right)=\bar{p}_{j}+a_{j}+b_{i}$. We focus on the choice of effort levels by group members that constitute a Nash

13. The latter interpretation is favored by Itoh (1991). The moral-hazard part of our story is similar to his model. 
equilibrium. ${ }^{14}$ Solving for the optimal values of $a_{i}$ and $b_{i}$, we get

$a_{i}=\frac{\alpha\{R-r(1+\gamma)\}+\gamma r p_{j}}{c_{1}}$

$b_{i}=\frac{(1-\alpha)\{R-r(1+\gamma)\}+\gamma r p_{i}}{c_{2}}$.

Substituting the values of $a_{i}$ and $b_{j}$ in $p_{i}$ and those of $a_{j}$ and $b_{i}$ in $p_{j}$ we get

$p_{i}=\bar{p}_{i}+A+B p_{j}$

$p_{j}=\bar{p}_{j}+A+B p_{i}$

where $A \equiv\{R-r(1+\gamma)\}\left\{\alpha / c_{1}+(1-\alpha) / c_{2}\right\}$ and $B \equiv \gamma r\left\{1 / c_{1}+1 / c_{2}\right\}$. Solving simultaneously, we get

$p_{i j}=\frac{1}{1-B^{2}}\left\{A(1+B)+\bar{p}_{i}+B \bar{p}_{j}\right\}$,

where $p_{i j}$ is the probability of success for type $i$ when its businessgroup partner is of type $j$. In the choice of the optimal contracts we need to make sure that $\gamma$ and $r$ satisfy the condition $B<1$ in order to have $p_{i j}>0$.

It is to be noted that the amount of effort supplied by the manager of firm $i$ on her own project depends on the type of project its partner firm $j$ has, because of the presence of a cross-guarantee. If firm $j$ is very likely to fail, then firm $i$ has lower incentives to supply effort to its own project, because of the higher level of expected crossguarantee payments. In contrast, the effort supplied by the manager of firm $i$ on the project of its partner firm $j$ is increasing in her own type. If firm $i$ is more likely to succeed, then firm $j$ 's expected crossguarantee payments are lower. Since firm $i$ gets a share of firm $j$ 's profits, her incentive to supply monitoring or helping effort is higher.

It is straightforward to check that Proposition 1 goes through, i.e., $\pi_{s s}+\pi_{r r}>\pi_{r s}+\pi_{s r}$. The proof is in the Appendix. The only difference from the previous section is that now the probability of success of a firm depends not only on its own type (as before), but also on the type of the firm that it is grouped with. As before, the value of having a safe firm as partner is higher for a safe firm, because it is more likely to be in a position to make cross-guarantee payments. Moreover, in this case its own probability of success is higher if it 
has a safe partner, through the choice of effort, which reinforces the former effect.

For a given $(r, \gamma)$ we can derive the optimal value of $\alpha$ by maximizing the payoff of a representative $i$-type borrower with respect to $\alpha$. The relevant condition is (see the Appendix for details)

$$
\frac{\{R-r(1+\gamma)\} \alpha+p_{i i} \gamma r}{\{R-r(1+\gamma)\}(1-\alpha)+p_{i i} \gamma r}=\frac{c_{2}}{c_{1}} \frac{1+\frac{\gamma r}{1-B}\left(\frac{1}{c_{1}}-\frac{1}{c_{2}}\right)}{1-\frac{\gamma r}{1-B}\left(\frac{1}{c_{1}}-\frac{1}{c_{2}}\right)} \text {. }
$$

Notice that the right-hand side is increasing in $c_{2}$ and decreasing in $c_{1}$, while the left-hand side is increasing in $\alpha$. Also, for $c_{1}=c_{2}, \alpha=\frac{1}{2}$. It immediately follows that $\alpha>\frac{1}{2}$ if $c_{2}>c_{1}$ and $\alpha<\frac{1}{2}$ if $c_{2}<c_{1}$. Intuitively, if eliciting own effort is less costly than eliciting monitoring effort (i.e., $c_{1}$ is lower than $c_{2}$ ), the level of equity holding should be higher in one's own firm than in a partner firm, and vice versa if $c_{1}$ is higher than $c_{2}$. The next step of our analysis will be simplified if we assume that the difference between $c_{1}$ and $c_{2}$ is not very large, so that $\alpha$ is in the neighborhood of $\frac{1}{2}$.

We can show that there exists a pair of financially interlinked contracts $\left(r_{s}, \gamma_{s}, \alpha_{s}\right)$ and $\left(r_{r}, \gamma_{r}, \alpha_{r}\right)$ such that risky projects with negative net surplus that were being funded under a standard pooling debt contract can be excluded. The proof is in the Appendix.

2.3.2 RISK SHARING. An alternative way to derive optimal equity cross-holdings is one using a risk-sharing model. Let us retain our basic model of Section 2 and add the feature that the borrowers are risk-averse and there is no market insurance available. Then efficient risk sharing dictates that firms within a business group smooth their income streams by holding claims on each other's projects' returns.

The expected payoff of a borrower of type $i$ that forms a business group with a borrower of type $j$ is now

$$
\begin{aligned}
\pi_{i j}= & p_{i} p_{j} u(R-r)+p_{i}\left(1-p_{j}\right) u(\alpha\{R-r(1+\gamma)\}) \\
& +\left(1-p_{i}\right) p_{j} u((1-\alpha)\{R-r(1+\gamma)\}) .
\end{aligned}
$$

Faced with any contract $(r, \gamma)$, any two firms would optimally share risk by choosing $\alpha=\frac{1}{2}$, which follows from maximizing $\pi_{i j}+\pi_{j i}$ with respect to $\alpha$. Intuitively, risk sharing within the group implies having the same income in each state of the world. Given this, we show that the assortative-matching and single-crossing properties still apply. In 
particular, the expected gain of a risky borrower from having a safe partner is

$p_{r}\left(p_{s}-p_{r}\right)\left\{u(R-r)-u\left(\frac{R-r(1+\gamma)}{2}\right)\right\}$,

while the expected loss of a safe borrower from having a risky partner is

$p_{s}\left(p_{s}-p_{r}\right)\left\{u(R-r)-u\left(\frac{R-r(1+\gamma)}{2}\right)\right\}$.

The former is less, as $p_{s}>p_{r}$. Given assortative matching, the expected payoff of a type $i$ borrower is

$\pi_{i i}=p_{i}^{2} u(R-r)+2 p_{i}\left(1-p_{i}\right) u\left(\frac{R-r(1+\gamma)}{2}\right)$.

The slope of an indifference curve of a type- $i$ borrower in the $(r, \gamma)$ plane is

$\frac{d r}{d \gamma}=-\frac{1}{\frac{1+\gamma}{r}+\frac{p_{i}}{1-p_{i}} \frac{u^{\prime}(R-r)}{u^{\prime}\left(\frac{R-r(1+\gamma)}{2}\right) r} .}$

It is clear upon inspection that indifference curves still satisfy the single-crossing property. From this the proof of Proposition 2 can be straightforwardly adapted to show that a pair of screening contracts exist such that only safe borrowers borrow in equilibrium.

\subsection{OTHER EXTENSIONS}

In the basic model we assumed that shocks facing firms are perfectly uncorrelated. Our model can be extended to allow for partial correlation in these shocks. However, if the shocks are perfectly correlated, then cross-holding of debt will not have any real effect and our results will no longer hold. If all firms within the business group fail, then there will be no debt repayment, nor any cross-guarantee payments. If they all succeed, there is no need for any cross-guarantee payments. Hence shocks facing firms within a business group must have an idiosyncratic component for business groups to solve the adverseselection problem. This assumption is justified by the fact that most business groups tend to be diversified or heterogeneous in their businesses. ${ }^{15}$

15. Fisman's (2001) paper on political connections in Indonesia is an example of a situation when shocks could be correlated. 
The assumption of competitive credit markets is without loss of generality. If the bank is a monopolist maximizing its expected profits, then the optimal contracts will be similar to those derived in the basic model, but they will lie on the respective participation constraints of the firms as opposed to the zero-profit constraints of the bank.

Cross-holdings of debt and equity in our model are symmetric within a business group. We allow borrowers to differ in a single characteristic, namely, the riskiness of their projects, and show that borrowers are going to sort in terms of this single characteristic. This leads to perfectly homogeneous groups, and hence, symmetric contracts. In reality, however, these contracts are often asymmetric: firm $A$ may hold a share $\alpha_{A}$ of its own returns, while firm $B$ may hold $\alpha_{B} \neq \alpha_{A}$ of its own returns. The same is possible regarding the extent of cross-holdings of debt, $\gamma$. A separate source of heterogeneity other than riskiness can be added to the model to generate asymmetric contracts within groups. A complete analysis of the issue of multidimensional heterogeneity is beyond the scope of this paper, and so we limit ourselves to the following example, based on the mutual-monitoring model. Suppose, after groups are formed and contracts are signed (so that regrouping is not feasible), each firm receives a mutually observable shock to the cost of monitoring with some probability. In particular, the cost of monitoring its partner firm becomes very high (i.e., $\left.c_{2} \rightarrow \infty\right)$ for a firm affected by this shock. Then there will be some business groups for which the members (say, $A$ and $B$ ) will have different costs of monitoring (i.e., $c_{2}^{A}<c_{2}^{B}$ ), and hence the optimal equity cross-holdings will be asymmetric (i.e, $\left.\alpha^{A} \simeq 1>\alpha^{B}\right) .{ }^{16}$

In our model we assume that borrowers have no wealth at all, which is clearly an unrealistic assumption. Suppose borrowers have some wealth $w>0$. In that case the bank will ask borrowers to pledge some collateral, which is taken away if the project fails. If this wealth level is high enough, the use of collateral will be sufficient to screen out risky borrowers. For our results to go through, all that is needed is a binding limited-liability constraint that implies that even if collateral is used, risky borrowers still prefer to borrow under a standard debt contract.

\section{EMPIRICAL IMPLICATIONS}

The analyses of the previous sections suggest ways to interpret existing empirical literature in the area and avenues for further empirical research. In this section we outline some of these ideas.

16. Other potential sources of heterogeneity are the profitability of the firm $(R)$, how much wealth a firm can put up as collateral (or equivalently, how much capital is needed), and risk aversion. 
The model suggests that the cost of borrowing should be correlated across group members and that the degree of cross-holding should be negatively correlated with the cost of borrowing. We believe these implications are potentially testable, using data on emergingmarket business groups.

For instance, several of the prominent business groups in countries such as South Korea and Mexico, where the prevalence of crossguarantees has been noted, borrow funds on the international debt market and consequently have been assigned international risk assessments (ratings) by investment advisory firms (such as Moody's Global Investor Service). The interest rate that these groups pay on such debt is also public information. Information on the extent of intragroup cross-liability is not available from public sources, but in principle it too should be obtainable. This would then allow the testing of the implications with regard to positive assortative matching in the formation of business groups and the screening of such groups by external lenders.

Another interesting implication of our theory for the study of business groups is their hierarchy, which is a hitherto unexplored dimension to such organizations. ${ }^{17}$ If, as the theory suggests, business groups are composed of firms with similar quality characteristics, then at first blush we would expect this to mean that actual groups should be composed of firms producing similar products. And indeed, we can use this interpretation to understand actual business groups composed of firms operating in similar markets. ${ }^{18}$ But how can we explain the existence of business groups composed of firms engaged in very diversified markets? ${ }^{19}$

There are two answers to this. First, while these firms may be engaged in very different markets, their activities may be similar in the quality dimension. ${ }^{20}$ Second, diversification in activities make the shocks facing group members less likely to be correlated, and the effect

17. It should be noted, however, that this implication is not unique to the specific mechanism for positive assortative matching suggested in this paper.

18. Such as Grupo Cemex of Mexico, which has firms engaged in the production of cement, contracting for bridge and building construction, and producing ancilliary construction materials.

19. For example, the House of Tata in India has interests in steel, watches, detergents, tea, automobiles, and computer software. Grupo Luksic of Chile has interests in banks, hotels, mining, beer, and pasta. Grupo Carso of Mexico has firms in telecoms, Internet services, television, department stores, and finance. See "When Eight Arms Are Better Than One," The Economist, Sept. 12, 1998, pp. 67-68.

20. Thus, although the House of Tata in India has interests in very diverse markets (steel, watches, detergents, tea, automobiles, and computer software) they are all perceived to be similar in quality-in this case, high quality, since Tata is considered a "blue-chip" brand. See Khanna et al. (1998) for more details on Tata. 
of debt cross-guarantees on efficiency crucially depends on the shocks being not perfectly correlated. If they were perfectly correlated, debt cross-guarantees would never bite. Either all firms would succeed, in which case there would be no need to pay up loan guarantees for a member firm, or all firms would default, in which case there would be nobody to pay loan guarantees. This perspective leads to a related implication. We can rank business groups according to the quality of their projects, suggesting a quality-based hierarchy. In fact, in many countries we do observe a class hierarchy of business groups, from the so-called "blue-chip" groups on down. In combination with the previous interpretation, this implies that we should expect to observe this kind of hierarchy among groups of related firms as well as among groups of diversified firms. Testing this would require obtaining risk ratings both on group-member firms and on the overall group. For prominent business groups in several emerging economies, one should be able to obtain or construct such indices.

The above observation is related to another robust recent empirical finding in the business-group literature. Studies covering various countries [see Khanna (2000) for an excellent survey] find that firms associated with business groups show better financial performance and productivity as well as better risk sharing than unaffiliated firms. While these may be explained by the presence of better mutual monitoring and risk sharing among business groups, our paper suggests the possibility of reverse causality. In particular, low-risk and highproductivity firms are precisely those that are likely to form business groups.

Recent empirical work on Chilean business groups by Khanna and Rivkin (1999) finds that equity interlocks explain a limited amount of covariance between earnings of business-group members. This suggests there are other mechanisms of financial interlinkage that contribute to the observed covariance, such as debt guarantees or intragroup loans, which are the main focus of this paper. ${ }^{21}$ Our paper suggests that future empirical work should pay greater attention to these alternative instruments of financial interlinkage.

An implication of the model is that if an economy is very networked and firms have access to good information about each other, financially interlinked debt contracts of the kind described in the paper should improve repayment rates. On the other hand, in economies with low levels of networking such contracts should reduce repayment rates. In a large economy such as India, it is well known 
that some business communities (such as the Marwaris) have much stronger close-knit networks than others. In principle it should be possible to obtain information on business groups composed of members of these communities and their repayment rates on loans, to test this implication.

Our results imply that the cross-holding of debt can be interpreted as a way to ameliorate adverse-selection problems in the credit market (in the absence of collateral), while cross-holding of equity provides incentives to mitigate moral-hazard problems. It is unlikely that either type of cross-holding by itself will solve both types of asymmetric information problems. Therefore, equity and debt crossholding arrangements may or may not go together, depending on whether both kinds of asymmetric problems are prevalent or not in a given economy. Empirically, this suggests we might be able to use the presence or absence of each of these types of arrangements, together with the presence or absence of collateral, as a marker for the kind of asymmetric-information problem that is more serious in a given economy.

The only role played by equity in our theory is as a device to elicit monitoring effort or to share risk. Debt has been the sole instrument available to firms for obtaining needed investment finance. This, of course, ignores the important role that the sale of shares plays in raising external funds. But the raising of capital through the sale of equity depends crucially on the existence of a well-functioning stock market and associated financial intermediation. A principal activity of these institutions is in fact the gathering and processing of information about firms, thereby easing the asymmetric information that is at the heart of our approach.

In many emerging and transition economies, the financial sector is still underdeveloped. Specialized financial intermediaries that perform informational and monitoring services are absent, or there is a serious lack of skills and incentives in such intermediaries as do exist. ${ }^{22}$ Stock markets do not work well. Indeed, there is empirical evidence that in many developing countries, stock markets are atrophied, with limited flotation and few listed firms [see Castañeda (1999) for Mexico, and Pistor (1999) for the Czech Republic, Hungary, and Poland]. Our model fits into such environments. Conversely, as the financial sector develops and information problems in the economy become less severe, we should expect to observe an unraveling of the kinds of ties that bind group firms that we have focused on in

22. For a theory of this, see Holmstrom and Tirole (1993). For empirical work, see Khanna and Palepu (1998b). 
this paper. This may be one way to understand why such business groups are rare in developed countries such as the US.

In a related vein, the past three years of financial crisis in South Korea may provide a laboratory to test our theory. As mentioned earlier, the clearest examples of debt and equity interlinkage come from the Korean chaebols. It is conceivable that the recent aggregate economic shock has also had idiosyncratic effects at the firm level that have altered the distribution of riskiness across Korean firms. In terms of our model, this means that the type of some firms may have changed, which would imply a change in the composition of groups. As we might expect in consequence, there is currently underway a process of unraveling of existing relationships and restructuring of many of the large Korean business groups. ${ }^{23}$ Once the economy stabilizes, it should be possible to examine whether the new groupings reflect a different distribution of riskiness across firms the way our assortative matching result suggests.

Recent cross-country empirical work across a spectrum of emerging economies ${ }^{24}$ by Singh (1995) shows that in developing countries, external finance takes precedence as a source of funds for firms. This is the reverse of the "pecking order" pattern of finance found in advanced economies, wherein firms mostly use retained profits to finance their investment needs, followed by long-term debt, with equity finance only as a last resort. Since firms in emerging economies are compelled to look toward external finance, credit rationing is likely to be a serious problem on account of the absence of adequate financial intermediation in these economies. Our analysis suggests that financially interlinked business groups can be interpreted as a solution to this problem.

\section{APPENDiX}

\section{A. 1 PROOF OF LEMMA 2}

It is easy to verify that the left-hand side of (6) is an increasing function of $\gamma_{s}$ and assumes the value $\left\{2 / p_{s}\left(2-p_{s}\right)\right\} \rho$ for $\gamma_{s}=1$. Similarly, the right-hand side of (5) is an increasing function of $\gamma_{s}$ and assumes the value $\left\{p_{r}\left(2-p_{r}\right) / p_{s}\left(2-p_{s}\right)\right\} \rho$ for $\gamma_{s}=1$. Observe that $p_{r} R-u<R$, and for any $\gamma_{s} \in[0,1],\left(1+\gamma_{s}\right) / p_{s}\left\{1+\gamma_{s}\left(1-p_{s}\right)\right\}>$ $p_{r}\left\{1+\gamma_{s}\left(1-p_{r}\right)\right\} / p_{s}\left\{1+\gamma_{s}\left(1-p_{s}\right)\right\}$. As $R>\rho / p_{s}$ [by (1)], for $\gamma_{s}=0$

23. See for instance the article "Entrepreneurial Fresh Air" in The Economist, Jan. 11, 2001.

24. India, Republic of Korea, Jordan, Pakistan, Thailand, Mexico, Malaysia, Turkey, and Zimbabwe. 
condition (6) is satisfied with strict inequality, and so it also holds for $\gamma_{s}$ small enough. However, for $\gamma_{s}=0$ condition (5) cannot hold, as it is equivalent to the condition $p_{r} R-u \leq\left(p_{r} / p_{s}\right) \rho$, which is ruled out by Assumption 2 [equation (2)], which says there is some inefficiency under standard debt contracts. A necessary condition for the existence of a $\gamma_{s} \in[0,1]$ that satisfies (5) is

$\frac{p_{r}\left(2-p_{r}\right)}{p_{s}\left(2-p_{s}\right)} \rho \geq p_{r} R-u$.

Note that $x(2-x)$ is increasing in $x$ for $x \in[0,1]$. Therefore $p_{r}\left(2-p_{r}\right)<$ $p_{s}\left(2-p_{s}\right)$, and the assumption that $p_{r} R-u<\rho$ in Assumption 1 [equation (1)] is not sufficient to ensure the condition (7) will hold. However, while necessary, (7) is not sufficient, as we have to check whether (6) is satisfied as well. There are two cases to consider. If (6) is satisfied for $\gamma_{s}=1$, which will be the case if $R \geq\left\{2 / p_{s}(2-\right.$ $\left.\left.p_{s}\right)\right\} \rho$, then it is satisfied for all $\gamma_{s} \in[0,1]$, and so we have proved the existence of a critical value $\hat{\gamma} \in(0,1)$ such that for all $\gamma_{s} \geq \hat{\gamma}$ a screening contract exists. Suppose $R<\left\{2 / p_{s}\left(2-p_{s}\right)\right\} \rho$ instead. Then there exists a $\gamma_{s} \in(0,1)$ such that $(6)$ holds with equality. This value of $\gamma_{s}$ is $\tilde{\gamma} \equiv\left(p_{s} R-\rho\right) /\left\{\rho-p_{s}\left(1-p_{s}\right) R\right\}$. Note that, as by assumption $R<\left\{2 / p_{s}\left(2-p_{s}\right)\right\} \rho$ in this case, we have $\tilde{\gamma} \in(0,1)$. A necessary and sufficient condition for a screening contract to exist in this case is that $\tilde{\gamma}$ must satisfy (5). Straightforward algebra shows that this condition is $p_{s} R \leq \rho+\left(p_{s}^{2} / p_{r}^{2}\right) u$. Observe that, as $p_{s}>p_{r}$, this condition is consistent with (1), which requires $p_{s} R>\rho+u$. This completes the proof.

\section{A.2 The Mutual-Monitoring Case}

A.2.1 Proof of assortative matching. The expected payoff of a firm of type $i$ that has a type- $j$ firm in its group when facing the contract $(r, \gamma, \alpha)$ is

$\pi_{i j}=\{R-r(1+\gamma)\}\left\{\alpha p_{i j}+(1-\alpha) p_{j i}\right\}+r \gamma p_{i j} p_{j i}-\frac{1}{2} c_{1} a_{i}^{2}-\frac{1}{2} c_{2} b_{i}^{2}$,

where $p_{i j}=\left\{1 /\left(1-B^{2}\right)\right\}\left\{A(1+B)+\bar{p}_{i}+B \bar{p}_{j}\right\}, a_{i}=[\alpha\{R-r(1+\gamma)\}+$ $\left.\gamma r p_{j i}\right] / c_{1}$ and $b_{i}=\left[(1-\alpha)\{R-r(1+\gamma)\}+\gamma r p_{i j}\right] c_{2}$. Then

$\frac{\partial^{2} \pi_{i j}}{\partial \bar{p}_{i} \partial \bar{p}_{j}}=\frac{r \gamma}{\left(1-B^{2}\right)^{2}}\left[\left(1-\frac{r \gamma}{c_{2}} B\right)+B\left(B-\frac{r \gamma}{c_{1}}\right)\right]>0$,

since $B=r \gamma\left(1 / c_{1}+1 / c_{1}\right)<1$ by assumption. Since the types of borrowers are complementary in the payoff functions, the assortative matching result follows directly from Becker (1993, Ch. 4). 
A.2.2 Derivation of the Optimal Value of $\alpha$. Since groups are homogeneous, the direct effect of a change in $\alpha$ cancels out. By the envelope theorem, we can ignore the effect of a change in $\alpha$ on $\pi_{i i}$ through variations in the level of the own effort level of a given firm. Rather, the choice of $\alpha$ is based on its effect on the other firm's effort level. Differentiating $\pi_{i i}$ with respect to $\alpha$ and using this fact, we get

$\left[\{R-r(1+\gamma)\} \alpha+p_{i i} \gamma r\right] \frac{\partial b_{i}}{\partial \alpha}-\left[\{R-r(1+\gamma)\}(1-\alpha)+p_{i i} \gamma r\right] \frac{\partial a_{i}}{\partial \alpha}=0$.

Since

$\frac{\partial a_{i}}{\partial \alpha}=\frac{R-r(1+\gamma)}{c_{1}}\left[1+\frac{\gamma r}{1-B}\left(\frac{1}{c_{1}}-\frac{1}{c_{2}}\right)\right]$

and

$\frac{\partial b_{i}}{\partial \alpha}=\frac{R-r(1+\gamma)}{c_{2}}\left[1-\frac{\gamma r}{1-B}\left(\frac{1}{c_{1}}-\frac{1}{c_{2}}\right)\right]$,

the condition in the main text follows.

\section{A.2.3 PROOF OF Existence OF SEPARATING CONTRACTS.} Notice that Lemma 1 applies with a minor modification: if incentivecompatible contracts $\left(r_{s}, \gamma_{s}, \alpha_{s}\right)$ and $\left(r_{r}, \gamma_{r}, \alpha_{r}\right)$ exist, then assortative matching still takes place. The proof consists of four steps.

Step 1: Take a given value of $\alpha \in(0,1)$ throughout this analysis. Consider a contract $(r, \gamma)$ such that the bank makes zero expected profits if only safe borrowers borrow under that contract. By construction,

$r p_{s s}\left\{1+\left(1-p_{s s}\right) \gamma\right\}=\rho$.

We want to show that under some conditions, if risky borrowers were to borrow under this contract, their expected payment to the bank would be higher than that of safe borrowers. Notice that both $p_{s s}$ and $p_{r r}$ depend on the specific contract $(r, \gamma)$ through endogenous effort choice. The condition that

$r p_{r r}\left\{1+\left(1-p_{r r}\right) \gamma\right\}>r p_{s s}\left\{1+\left(1-p_{s s}\right) \gamma\right\}$

simplifies to

$p_{s s}+p_{r r}>\frac{1}{1+\gamma}+1$.

Clearly, this condition cannot hold for $\gamma=0$. However, for a large enough value of $\gamma$ it will be satisfied. For example, when $\gamma=1$, this condition is equivalent to $\bar{p}_{s}+\bar{p}_{r}>\left\{\frac{3}{2}-2 A /(1-B)\right\}(1-B)$. Since $B<1$ and $A /(1-B)<1$ by assumption, the condition will be satisfied for a range of values of $\bar{p}_{s}$ and $\bar{p}_{r}$. 
Step 2: In the previous step we considered only a part of the expected payoff of a firm, namely, the expected payment to the bank. Consider the remaining component of the expected payoff of a borrower of type $i$ (say $\tilde{\pi}_{i i}$ ), namely, $p_{i i} R-\frac{1}{2} c_{1} a_{i}^{2}-\frac{1}{2} c_{2} b_{i}^{2}$. As before, consider a contract $(r, \gamma)$ such that the bank makes zero expected profits if only safe borrowers borrow under that contract, i.e., $r p_{s s}\left\{1+\left(1-p_{s s}\right) \gamma\right\}=\rho$. Consider a simple debt contract $\left(r^{\prime}, 0\right)$ such that $p_{s s} r^{\prime}=\rho$. We wish to show that $\tilde{\pi}_{r r}(r, \gamma, \alpha)<\tilde{\pi}_{r r}\left(r^{\prime}, 0, \alpha\right)$, i.e.,

$\left(\bar{p}_{r}+a_{r}+b_{r}\right) R-\frac{1}{2} c_{1} a_{r}^{2}-\frac{1}{2} c_{2} b_{r}^{2}<\left(\bar{p}_{r}+\tilde{a}_{r}+\tilde{b}_{r}\right) R-\frac{1}{2} c_{1} \tilde{a}_{r}^{2}-\frac{1}{2} c_{2} \tilde{b}_{r}^{2}$

where $a_{i}=\left[\alpha\{R-r(1+\gamma)\}+\gamma r p_{i i}\right] / c_{1}$ and $b_{i}=[(1-\alpha)\{R-r(1+\gamma)\}+$ $\left.\gamma r p_{i i}\right] / c_{2}$ are the effort choices of a firm of type $i$ under the contract $(r, \gamma)$, while $\tilde{a_{i}}=\alpha\left(R-r^{\prime}\right) / c_{1}$ and $\tilde{b}_{i}=(1-\alpha)\left(R-r^{\prime}\right) / c_{2}$ are effort choices of a firm of type $i$ under the contract $\left(r^{\prime}, 0\right)$. Since effort levels are lower than what would be achieved if these were contractible (namely, $a^{*}=R / c_{1}$ and $b^{*}=R / c_{2}$ ), if we can show that $\tilde{a}_{r}>a_{r}$ and $\tilde{b}_{r}>b_{r}$, the proof will be complete. That is, we require

$$
\alpha\left\{r(1+\gamma)-r^{\prime}\right\}-\gamma r p_{r r}>0, \quad(1-\alpha)\left\{r(1+\gamma)-r^{\prime}\right\}-\gamma r p_{r r}>0 .
$$

Recall that by construction $r p_{s s}\left\{1+\left(1-p_{s s}\right) \gamma\right\}=p_{s s} r^{\prime}$. Therefore, $r(1+$ $\gamma)-r^{\prime}=\gamma r p_{s s}>\gamma r p_{r r}$. Hence, so long as $\min \{\alpha, 1-\alpha\} p_{s s}>p_{r}$, this condition will be satisfied. So long as $\bar{p}_{s}$ is large enough compared to $\bar{p}_{r}$ and $\alpha$ is neither too close to 1 nor too close to 0 , that condition in turn will be satisfied. Since we assume $c_{1}$ and $c_{2}$ are close enough, we are guaranteed that $\alpha$ does not take extreme values.

Step 3: We must make sure that safe borrowers are strictly better off under the contract $(r, \gamma)$ than under the contract $\left(r^{\prime}, 0\right)$. Step 1 already shows that their expected payment to the bank is the same. Now we look at the remaining component of their payoff, $\tilde{\pi}_{s s}$. The argument is similar to the one used in step 2, but the aim is exactly the opposite. Now we want to show that $\tilde{a}_{s}<a_{s}$ and $\tilde{b}_{s}<b_{s}$, whereas previously we wanted to show that $\tilde{a}_{r}>a_{r}$ and $\tilde{b}_{r}>b_{r}$. Since $\alpha\left\{r(1+\gamma)-r^{\prime}\right\}-\gamma r p_{s s}=$ $-(1-\alpha) \gamma r p_{s s}<0$ and $(1-\alpha)\left\{r(1+\gamma)-r^{\prime}\right\}-\gamma r p_{s s}=-\alpha \gamma r p_{s s}<0$, our proof is complete.

Step 4: Starting with a situation where risky borrowers borrowing under a standard pooling debt contract $\left(r^{\prime}, 0\right)$, suppose the contract $(r, \gamma)$ is offered. Safe borrowers will be better off, and under some parameter conditions risky borrowers will be strictly worse off. If the expected payoff of risky borrowers, $\pi_{r r}$, falls below $u$, then they will withdraw from the credit market, thereby improving efficiency. 


\section{REFERENCES}

Aoki, M., 1982, "Business Groups in a Market Economy," European Economic Review, 19, 3-70.

Bebchuk, L., R. Kraakman, and G. Triantis, 1998, "Stock Pyramids, Cross-Ownership, and Dual Class Equity: The Creation and Agency Costs of Separating Control from Cash Flow Rights," Mimeo, Harvard Law School.

Becker, G., 1993, A Treatise on the Family, Cambridge, MA: Harvard University Press.

Berglof, E. and E. Perotti, 1994, "The Governance Structure of the Japanese Financial Keiretsu," Journal of Financial Economics, 36, 259-284.

Bester, H., 1987, "The Role of Collateral in Credit Markets with Imperfect Information," European Economic Review, 31, 887-899.

Brioschi, F., L. Buzzacchi, and M. Colombo, 1989, "Risk Capital Financing and the Separation of Ownership and Control in Business Groups," Journal of Banking and Finance, 13, 747-772.

Calomiris, C., 1990, “Is Deposit Insurance Necessary? A Historical Perspective," Journal of Economic History, 50, 283-295.

Castañeda, G., 1998, La Empresa Mexicana y Su Gobierno Corporativo (The Mexican Firm and Its Corporate Governance), Alter Ego/UDLAP Press.

1999, "Laggard Economic Growth and Ill-Functioning Stock Markets," Mimeo, Universidad de Las Americas, Puebla, Mexico.

Clayton, M.J. and B.N. Jorgensen, 2000, "Cross Holding and Imperfect Product Markets," Mimeo, Harvard Business School.

De Meza, D. and D. Webb, 1987, "Too Much Investment: A Problem of Asymmetric Information," Quarterly Journal of Economics, 102 (2), 281-292.

Fisman, R., 2001, "Estimating the Value of Political Connections," American Economic Review, forthcoming.

Ghatak, M., 2000, "Screening by the Company You Keep: Joint Liability Lending and the Peer Selection Effect," Economic Journal, 110 (465), 601-631.

Ghemawat, P. and T. Khanna, 1998, "The Nature of Diversified Business Groups: A Research Design and Two Case Studies," Journal of Industrial Economics, 66 (1), 35-61.

Goto, A., 1982, "Business Groups in a Market Economy," European Economic Review, 19, 53-70.

Granovetter, M., 1994, "Business Groups," in N.J. Smelser and R. Swedberg, eds., The Handbook of Economic Sociology, Princeton University Press.

Holmstrom, B. and J. Tirole, 1993, "Market Liquidity and Performance Monitoring," Journal of Political Economy, 101 (4), 679-707.

Itoh, H., 1991, "Incentives to Help in Multi-agent Situations," Econometrica, 59 (3), 611-636.

Kali, R., 1999b, "Business Groups, the Financial Market and Modernization," Mimeo, University of Arkansas.

Khanna, T., 2000, "Business Groups and Social Welfare in Emerging Markets: Existing Evidence and Unanswered Questions," European Economic Review, 44, 748-761.

- and K. Palepu, 1998a, "Is Group Affiliation Profitable in Emerging Markets? An Analysis of Indian Diversified Business Groups," Working Paper 96-051, Harvard Business School; Journal of Finance, 55 (2), 867-891.

- and _ 1998b, "Emerging Market Business Groups, Foreign Investors and Corporate Governance," Working Paper No. 6955, Cambridge, MA: National Bureau of Economic Research. 
and J.W. Rivkin, 1999, "Ties That Bind Business Groups: Evidence from Chile," Mimeo, Harvard Business School.

and Y. Yafeh, 1999, "Business Groups and Risk Sharing around the World," Mimeo, Harvard Business School.

- K. Palepu, and D.M. Wu, 1998, The House of Tata: The Next Generation (A), Case 9-798-037, Harvard Business School Publishing.

Keister, L., 2000, Chinese Business Groups: The Structure and Impact of Interfirm Relations during Economic Development, Oxford University Press.

La Porta, R., F. Lopez-De-Silanes, and A. Shleifer, 1999, “Corporate Ownership around the World," Journal of Finance, 54 (2) 471-517.

Lincoln, J.R., M.L. Gerlach, and C.L. Ahmadjian, 1996, "Keiretsu Networks and Corporate Performance in Japan," American Sociological Review, 61, 67-88.

Matsusaka, J.G., 2000, "Corporate Diversification, Value Maximization, and Organizational Capabilities," Journal of Business, 74 (3), 409-432.

Morduch, J., 1999, "The Microfinance Promise," Journal of Economic Literature, 37 (4), 1564-1614.

Nakatani, I., 1984, "The Economic Role of Financial Corporate Grouping," in M. Aoki, ed., The Economic Analysis of the Japanese Firm, New York: North Holland.

Pistor, K., 1999, "Law as a Determinant for Equity Market Development: The Experience of Transition Economies," in P. Murrell, ed., Assessing the Value of Law in the Economic Transition from Socialism, Ann Arbor, MI: University of Michigan Press.

Shin, H.H. and Y.S. Park, 1999, "Financing Constraints and Internal Capital Markets: Evidence from Korean Chaebols," Journal of Corporate Finance, 5, 169-191.

Singh, A., 1995, "Corporate Financing Patterns in Industrializing Economies: A Comparative International Study," Technical Paper No. 2, International Finance Corporation.

Stiglitz, J. and A. Weiss, 1981, "Credit Rationing in Markets with Imperfect Information," American Economic Review, 71 (3), 393-410.

Wolfenzon, D., 1999, "A Theory of Pyramidal Ownership," Mimeo, University of Michigan. 